\title{
Differential Change in Oculomotor Performance among Female Collegiate Soccer Players versus Non-Contact Athletes from Pre- to Post-Season
}

\author{
Virginia T. Gallagher, ${ }^{1, *}$ Prianka Murthy, ${ }^{1}$ Jane Stocks, ${ }^{1}$ Brian Vesci, ${ }^{2}$ Danielle Colegrove, ${ }^{2}$ Jeffrey Mjaanes, ${ }^{2}$ Yufen Chen, ${ }^{3}$
} Hans Breiter, ${ }^{1}$ Cynthia LaBella, ${ }^{4}$ Amy A. Herrold, ${ }^{1,5}$ and James L. Reilly ${ }^{1}$

\begin{abstract}
Sensitive and reliable tools are needed to evaluate potential behavioral and cognitive changes following head impact exposure in contact and collision sport participation. We evaluated change in oculomotor testing performance among female, varsity, collegiate athletes following variable exposure to head impacts across a season. Female, collegiate, contact sport (soccer, CONT) and non-contact sport (NON-CONT) athletes were assessed pre-season and post-season. Soccer athletes were grouped according to total season game headers into low dose ( $\leq 40$ headers; CONT-Low Dose) or high dose (>40 headers; CONT-High Dose) groups. Performance on pro-saccade (reflexive visual response), anti-saccade (executive inhibition), and memory-guided saccade (MGS, spatial working memory) computer-based laboratory tasks were assessed. Primary saccade measures included latency/reaction time, inhibition error rate (anti-saccade only), and spatial accuracy (MGS only). NON-CONT $(n=20)$, CONT-Low Dose $(n=17)$, and CONT-High Dose $(n=7)$ groups significantly differed on pre-season versus post-season latency on tasks with executive functioning demands (anti-saccade and MGS, $p \leq 0.001$ ). Specifically, NON-CONT and CONT-Low Dose demonstrated shorter (i.e., faster) anti-saccade (1.84\% and 2.68\%, respectively) and MGS (5.74\% and $2.76 \%$, respectively) latencies from pre-season to post-season, whereas CONT-High Dose showed $1.40 \%$ average longer anti-saccade, and $0.74 \%$ shorter MGS, latencies. NON-CONT and CONT-Low Dose demonstrated reduced (i.e., improved) inhibition error rate on the anti-saccade task at post-season versus pre-season, whereas CONT-High Dose demonstrated relative stability $(p=0.021)$. The results of this study suggest differential exposure to subconcussive head impacts in collegiate female athletes is associated with differential change in reaction time and inhibitory control performances on executive saccadic oculomotor testing
\end{abstract}

Keywords: oculomotor; repetitive head impacts; saccade testing; soccer subconcussion

\section{Introduction}

Participation in contact and collision sports increases an individual's exposure to head impacts, which may yield concussive or subconcussive injuries. Subconcussive injuries occur in the absence of clinical signs or symptoms, but pathophysiological changes in the brain, including vasculature and white matter alterations, may occur and may have cumulative adverse effects over time. ${ }^{1-4}$ Some studies suggest chronic exposure to repetitive head impacts may be associated with

\footnotetext{
${ }^{1}$ Department of Psychiatry and Behavioral Sciences, Northwestern University Feinberg School of Medicine, Chicago, Illinois, USA.

${ }^{2}$ Department of Sports Medicine, Northwestern University, Evanston, Illinois, USA.

${ }^{3}$ Center for Translational Imaging, Northwestern University, Chicago, Illinois, USA.

${ }^{4}$ Division of Orthopedics and Sports Medicine, Ann and Robert H. Lurie Children's Hospital of Chicago, Chicago, Illinois, USA.

${ }^{5}$ Edward Hines, Jr. VA Hospital, Hines, Illinois, USA.
}

*Address correspondence to: Virginia T. Gallagher, MS, Department of Psychiatry and Behavioral Sciences, Northwestern University Feinberg School of Medicine, 710 N. Lake Shore Drive, Chicago, IL 60611, USA, E-mail: Va.t.gallagher@gmail.com 
increased risk of long-term neurocognitive deficits and neuropsychiatric disorders. ${ }^{2,5-7}$

Neuroimaging studies evaluating change associated with subconcussive impacts occurring across an athletic season report longitudinal alterations in white matter structure, neurometabolism, and functional activation. $^{8-15}$ Prospective studies examining the relationship between subconcussive impacts and cognitive functioning have yielded mixed findings, with some reporting decline following impact exposure (in domains such as working memory, processing speed, and verbal learning and memory), ${ }^{15-19}$ and others observing no change. ${ }^{20-26}$ Given that cognitive change is seen variably, ${ }^{7}$ it is possible a more sensitive measure is needed to reliably detect subtle changes associated with subconcussive impacts. Saccadic oculomotor testing demonstrates promising sensitivity and specificity for distinguishing individuals with and without exposure to head trauma. ${ }^{27-30}$

Saccades are rapid eye movements from one point to another and can be initiated automatically or voluntarily using top-down executive control. ${ }^{31}$ Laboratorybased saccadic eye movement tasks have been used to probe brain dysfunction as the underlying neural circuitry involved in the execution of saccades is well delineated by human and animal anatomical and physiological research. ${ }^{31}$ Classic saccadic oculomotor tasks include the: 1) pro-saccade task, which measures reflexive shifts of visual attention by prompting participants to look toward a target when it appears; 2) anti-saccade task, which probes inhibition and speed of executive shifts of visual attention by requiring participants to look away from a target when it appears, and 3) memoryguided saccade (MGS) task, which probes working memory ability by prompting participants to look toward a remembered location of a previously presented target after a variable delay period.

A recent meta-analysis revealed that athletes with sports-related concussion perform worse than controls on select aspects of saccade tasks with executive functioning demands, including increased inhibitory errors on anti-saccade and MGS tasks and poorer spatial working memory accuracy on the MGS task. ${ }^{32}$ Further, there is evidence that compared with controls, recently concussed individuals demonstrate longer reaction time on executive saccade tasks, with performance typically normalizing 1 to 2 weeks post-injury. ${ }^{33-35}$ Findings in the literature are inconsistent as to whether oculomotor saccade performance is sensitive to the effects of remote history of concussion. ${ }^{36-38}$ To date, no known studies have investigated the sensitivity of eye movement testing to detect potential effects of recent exposure to subconcussive head impacts sustained across a sports season.

The primary aim of this study was to evaluate whether saccadic oculomotor testing detects differential change in cognitive and sensorimotor processing following variable levels of exposure to head impacts among female contact sport (soccer) and non-contact sport collegiate athletes. Given that executive saccade tasks, such as the anti- and MGS tasks, have been more sensitive to the effects of concussion, relative to the less cognitively demanding pro-saccade task, ${ }^{32}$ we hypothesized that the anti-saccade and MGS tasks would demonstrate sensitivity to the effects of head impact exposure. Specifically, we hypothesized that contact athletes, particularly with higher estimated exposure to head impacts would demonstrate longer anti-saccade and MGS latencies, increased anti-saccade error rate, and reduced MGS accuracy from pre- to post-season (reflecting reduced executive attentional control and working memory ability), compared with non-contact athletes, who would demonstrate relative stability or improvement (reflecting practice effects) over time.

\section{Methods}

\section{Study design and setting}

This prospective, longitudinal study evaluated oculomotor performance among female collegiate athletes assessed pre-season and post-season. Athletes were assigned to the following groups: a) non-contact sport athletes (NON-CONT); b) low-dose contact sport (soccer) athletes who sustained $\leq 40$ headers in games/season (CONT-Low Dose); and c) high-dose contact sport (soccer) athletes who sustained $>40$ headers in games/season(CONT-High Dose), based on post hoc distribution of header data collected over the season (see Supplementary Fig. S1).

All CONT pre-season assessments were completed prior to the initiation of official pre-season training and at least 4 weeks following the most recent competitive, post-season scrimmage. Post-season procedures occurred within 4-11 days of the end of the competitive season (mean [standard deviation; SD], days $=7.43$ [2.50]). NON-CONT athletes were evaluated during similar time frames to match the duration between pre-season and post-season assessments as closely as logistically possible among groups. 
Participants and recruitment

Division 1, female, collegiate varsity athletes (18-25 years) were recruited $(n=48)$ and none met exclusion criteria: history of recent concussion prior to study entry ( $<30$ days), ${ }^{28-30}$ moderate to severe traumatic brain injury, ${ }^{39}$ lifetime diagnosis or family history of a psychotic disorder, ${ }^{40,41}$ seizure disorder, ${ }^{42}$ or vision abnormalities (aside from wearing contacts or glasses for vision correction). The NON-CONT group consisted of golf, swimming, and tennis athletes.

To examine a dose effect of impact exposure among female soccer players, athletes' headers, defined as contact between the player's head and the ball, were recorded live during games by two independent athletic trainers, with any discrepancies resolved by review of game recordings. Headers sustained during practices were not recorded. Based on the distribution of total game headers per season across the CONT group (Supplementary Fig. S1), CONT athletes were divided into CONT-Low Dose ( $\leq 40$ headers in games/season, $n=17$ ) and CONTHigh Dose ( $>40$ headers in games/season, $n=7$ ) groups.

This study was approved by Northwestern University's Institutional Review Board; all participants completed informed consent procedures prior to participation and were compensated $\$ 30$ and $\$ 45$ each for completion of the pre-season study visit and postseason study visit, respectively.

\section{Oculomotor testing}

Eye movement recordings were obtained using the SR Research camera-based eye tracking system, EyeLink 1000 Plus, with a sampling speed of $2000 \mathrm{~Hz}$. Assessments were conducted in a window-less room and a non-restrictive chin and forehead rest stabilized participant head position, maintained a fixed position across subject to visual stimuli, and improved quality of eye trace. Pupil size and corneal reflection thresholds were adjusted for each subject to ensure consistent trace from both eyes. Saccades were automatically detected by the EyeLink system when eye position moved more than 0.15 degrees from fixation and trace exceeded velocity and acceleration thresholds of 30 degrees/sec and 8000 degrees $/ \mathrm{sec}^{2}$, respectively.

See Table 1 for oculomotor task information. Pro- and anti-saccade tasks consisted of gap, no gap, and overlap trials. On no gap trials, the central target extinguished

Table 1. Oculomotor Task Information

\begin{tabular}{|c|c|c|c|c|}
\hline Task (duration) & Overview & Primary measure(s) & Directions to participant & Design \\
\hline $\begin{array}{l}\text { Pro-saccade } \\
\qquad(10 \mathrm{~min})\end{array}$ & $\begin{array}{l}\text { An automatic or } \\
\text { reflexive } \\
\text { attention task. }\end{array}$ & $\begin{array}{l}\text { Primary saccade latency, } \\
\text { gain, accuracy, } \\
\text { duration, and peak } \\
\text { velocity. }\end{array}$ & $\begin{array}{l}\text { Participants are instructed to look at } \\
\text { visual targets when they appear. }\end{array}$ & $\begin{array}{l}96 \text { trials that begin with a center } \\
\text { fixation target that remains } \\
\text { illuminated for } 1.5-2.5 \mathrm{sec} \text { before } \\
\text { peripheral targets appear at } \\
10 \text { degrees or } 15 \text { degrees from } \\
\text { center in the left or right visual } \\
\text { field; three conditions ( } 32 \text { trials } \\
\text { each) are conducted to } \\
\text { manipulate the center fixation } \\
\text { offset and peripheral target } \\
\text { onset: gap, no gap, and overlap. }\end{array}$ \\
\hline $\begin{array}{l}\text { Anti-saccade } \\
\quad(10 \mathrm{~min})\end{array}$ & $\begin{array}{l}\text { An executive or } \\
\text { voluntary } \\
\text { attention task. }\end{array}$ & $\begin{array}{l}\text { Antisaccade error rate } \\
\text { (error trials/total trials) } \\
\text { and primary saccade } \\
\text { latency. Errors occur } \\
\text { when participants } \\
\text { incorrectly look } \\
\text { toward the peripheral } \\
\text { target. }\end{array}$ & $\begin{array}{l}\text { Participants are instructed to inhibit } \\
\text { the automatic response to look } \\
\text { toward the peripheral target and } \\
\text { instead shift their gaze to the } \\
\text { mirrored location (e.g., if target } \\
\text { appears } 3 \text { in to the left of center, } \\
\text { participants look immediately } 3 \\
\text { in to the right of center). }\end{array}$ & $\begin{array}{l}96 \text { trials that begin with a center } \\
\text { fixation target that remains } \\
\text { illuminated for } 1.5-2.5 \mathrm{sec} \text { before } \\
\text { peripheral targets appear at } 10 \\
\text { degrees or } 15 \text { degrees from } \\
\text { center in the left or right visual } \\
\text { field; three conditions ( } 32 \text { trials } \\
\text { each) are conducted to } \\
\text { manipulate the center fixation } \\
\text { offset and peripheral target } \\
\text { onset: gap, no gap, and overlap. }\end{array}$ \\
\hline $\begin{array}{l}\text { Memory-guided } \\
\text { saccade } \\
\text { (20 min) }\end{array}$ & $\begin{array}{l}\text { An executive, } \\
\text { working } \\
\text { memory task. }\end{array}$ & $\begin{array}{l}\text { Primary saccade latency, } \\
\text { spatial accuracy, and } \\
\text { delay duration error } \\
\text { rate (errors occur } \\
\text { when the participant } \\
\text { incorrectly looks } \\
\text { toward the target } \\
\text { during the delay } \\
\text { period). }\end{array}$ & $\begin{array}{l}\text { Participants are instructed to } \\
\text { maintain gaze on the central } \\
\text { fixation stimulus; after a short } \\
\text { delay, a peripheral target appears } \\
\text { very briefly as participants } \\
\text { continue to fixate on the central } \\
\text { stimulus. When the central } \\
\text { fixation stimulus disappears after } \\
\text { a brief delay, participants shift } \\
\text { their gaze to the remembered } \\
\text { location of the peripheral target. }\end{array}$ & $\begin{array}{l}80 \text { trials that begin with a center } \\
\text { fixation target that remains while } \\
\text { the peripheral target (at } 6 \\
\text { degrees, } 8 \text { degrees, } 10 \text { degrees, } \\
12 \text { degrees, and } 14 \text { degrees from } \\
\text { center in the left or right visual } \\
\text { field) appears and extinguishes } \\
\text { with variable delay duration } \\
\text { period }(1,2,4,8 \mathrm{sec}) \text {. }\end{array}$ \\
\hline
\end{tabular}


simultaneously with the peripheral target appearance, whereas the central target was extinguished $200 \mathrm{msec}$ prior to, or following, the peripheral target appearance on gap and overlap trials, respectively. The order of condition administration within the pro- and antisaccade tasks was randomized by participant but was consistent within participant at both visits.

Primary variables of interest included saccade latency, defined as the time (in milliseconds) between the cue to respond and the initiation of a saccade, which reflects the speed of reflexive shifts of visual attention on the pro-saccade task and the speed of executive or voluntary shifts of attention on the antisaccade and MGS tasks. On the pro-saccade task, in addition to latency, other measurements of interest included: a) gain: the spatial accuracy of the saccade to the target location, which is derived from the ratio of the saccade amplitude to the target amplitude; b) accuracy: the spatial accuracy of the primary saccade, derived from the difference between the location of the target position and the location of the end point of the primary saccade (in x-coordinate pixels); c) duration: the time (in milliseconds) taken to complete a saccade; and d) peak velocity (degree/sec): the highest velocity reached during the saccade, which is linearly related to the saccade duration. Anti-saccade error rate, the ratio of error trials (in which a participant incorrectly looks to a target when it appears) to total trials, is a measure of executive response inhibition and cognitive control. MGS accuracy, the percentage of distance (overshoot or undershoot) of the saccade to the remembered location, is a measure of spatial working memory precision.

\section{Questionnaires and self-reported symptom data}

Prior to in-person study assessments, all participants completed a comprehensive questionnaire regarding demographic, health history (including concussion history), recent athletic participation information, educational background, and parental education and occupational history (to yield a total socioeconomic status score).

All athletes completed several online self-report questionnaires within $24 \mathrm{~h}$ of eye movement testing at both visits to assess the influence of physical, cognitive, and emotional symptoms on oculomotor performance. Questionnaires included the Post-Concussion Symptom Scale (PCSS) to assess the severity of physical, cognitive, and emotional symptoms that occur in both concussed and healthy populations; ${ }^{43}$ the Beck Depression Inventory-II (BDI-II) to assess symptoms of depression; ${ }^{44,45}$ the State-Trait Anxiety Inventory (STAI) to assess anxiety, ${ }^{46}$ and the Perceived Stress Scale (PSS) to assess the ability to handle stress. ${ }^{47,48}$

\section{Participation data}

Senior athletic trainers recorded participant attendance and participation in practices and games to ensure adequate engagement in athletics and no prolonged ( $>14$ day) absences due to injury. To ensure comparable exposure to recent exercise and competition at the post-season visit, the duration between the dates of most recent sports participation and post-season assessments were calculated for each player and compared among groups.

\section{Statistical analysis}

See eMethods in Supplementary Appendix S1 for oculomotor data scoring and cleaning procedures established in our laboratory. ${ }^{49}$ Statistical analyses were performed using IBM SPSS Statistics for Windows, version 25.0. ${ }^{50}$ Descriptive analyses were conducted to evaluate group differences in demographic, clinical history information, and mood/behavioral symptom data; specific tests included one-way analyses of variance and chi-square tests for parametric data and Kruskal-Wallis analyses for non-parametric data. General linear mixed modeling was used to evaluate group differences on oculomotor measures of interest within task. For pro-saccade latency, anti-saccade latency (correct trials only), and anti-saccade error rate, effects analyzed included visit (pre-season versus post-season), group (NON-CONT vs. CONT-Low Dose vs. CONTHigh Dose), condition (gap, no gap, overlap), the twoway interaction of visit-by-group, and the three-way interaction of visit-by-group-by-condition. Given that the experimental manipulation of the offset of the central fixation target primarily affects latency and anti-saccade error rate, all other pro-saccade analyses (gain, accuracy, duration, and peak velocity) were conducted on no gap condition trials only. For MGS latency and accuracy of the primary saccade and resting position, effects analyzed included visit, group, delay period duration (1-, 2-, 4-, or 8-sec delay period duration), the two-way interaction of visit-by-group, and the three-way interaction of visit-by-group-bydelay period duration.

If an effect was not significant $(p>0.05)$ in the model, it was removed from the model, and main 
Table 2. Sample Demographics and Characteristics

\begin{tabular}{|c|c|c|c|c|}
\hline & NON-CONT $(\mathrm{n}=20)$ & CONT-low dose $(\mathrm{n}=17)$ & CONT-high dose $(\mathrm{n}=7)$ & P-value \\
\hline Age, mean (SD), years & $19.50(1.40)$ & $19.24(1.44)$ & $20.14(1.21)$ & ns \\
\hline Caucasian (\%) & $13(65 \%)$ & $14(82 \%)$ & $7(100 \%)$ & ns \\
\hline Years of education, mean (SD) & $13.35(1.18)$ & $12.71(1.05)$ & $13.43(0.98)$ & ns \\
\hline Socioeconomic status, mean (SD) ${ }^{a}$ & $150.00(24.58)$ & $141.00(23.82)$ & $149.33(10.01)$ & ns \\
\hline Hx of anxiety or depression (\%) & $2(10 \%)$ & $2(12 \%)$ & $2(29 \%)$ & ns \\
\hline Hx of LD or ADHD $(\%)^{b}$ & $1(5 \%)$ & $0(0 \%)$ & $2(29 \%)$ & 0.038 \\
\hline Hx of $1+$ previous concussion ${ }^{b}$ & $0(0 \%)$ & $7(41 \%)$ & $4(57 \%)$ & 0.002 \\
\hline Weeks between pre- and post-season visits, mean (SD) & $18.00(3.67)$ & $20.59(14.11)$ & $19.71(2.98)$ & ns \\
\hline
\end{tabular}

${ }^{a}$ Represents Hollingshead 4-factor score; ${ }^{b}$ despite significant group differences, variable was not associated with oculomotor performance at baseline or change over time.

ADHD, attention-deficit/hyperactivity disorder; $\mathrm{Hx}$, History; LD, learning disability; ns, not significant ( $p>0.05)$; SD, standard deviation.

effects of interest were retained (i.e., visit-by-group or visit-by-group-by-condition) for a repeat analysis. Multiple repeated covariance structure types were tested for each model, and the repeated covariance structure with the lowest Akaike Information Criteria (AIC), indicating the best model fit, was selected for final analysis. ${ }^{51}$ The original alpha level $(p<0.05)$ was adjusted for multiple comparisons using the Bonferroni correction across the four main hypotheses to yield a new alpha level of $p<0.0125$.

\section{Results}

See Table 2 for sample characteristics among NONCONT $(n=20)$, CONT-Low Dose $(n=17)$, and CONTHigh Dose $(n=7)$. Two participants ( $[n=1$, CONT-Low Dose] and $[n=1, \mathrm{NON}-\mathrm{CONT}])$ from the original sample were lost to follow-up. One NON-CONT athlete was excluded post hoc due to in-season orthopedic injury, and one NON-CONT was excluded due to invalid performance. Participant dropout and exclusion rates did not differ among groups. One CONT-High Dose athlete sustained a concussion 18 days prior (with medical clearance 9 days prior) to the postseason visit. This participant's oculomotor measures were within \pm 1 SD of the CONT-High Dose group means. Results of analyses remained consistent with and without inclusion of this participant; as such, this participant was retained. Groups did not differ on the average number of days between most recent game or practice and the post-season visit. Groups significantly differed by history of previous concussion and history of learning disability and/or attention-deficit/hyperactivity disorder (ADHD); none of these variables were associated with oculomotor performance at baseline or change over time. There were no significant differences in self-reported symptoms of depression, anxiety, stress, or concussion-related symptoms at pre-season or post- season, nor were there were significant group-by-time interaction effects (see Table 3).

Regarding position, the CONT-Low Dose group was comprised of approximately $47 \%$ midfielders, $24 \%$ forwards, $18 \%$ goalkeepers, and $12 \%$ defenders and the group average of game playing time was $495 \mathrm{~min}$ $(\mathrm{SD}=470)$. The CONT-High Dose group was comprised of approximately $57 \%$ midfielders and $43 \%$ defenders with a group average of $1594 \mathrm{~min}(\mathrm{SD}=156)$ of game playing time. Although we did not have header data for practices, it is reasonable to assume players in the CONT-High Dose group sustained an overall greater frequency of head impacts throughout the season given data in the literature suggesting female college soccer players sustain two times the frequency of head impacts during games versus practices. ${ }^{52}$ Further, the distribution of positions across the groups is not surprising given data demonstrating higher mean header

Table 3. Group Mood and Symptom Data

\begin{tabular}{lccc}
\hline & $\begin{array}{c}\text { NON-CONT } \\
(\mathbf{n}=\mathbf{2 0})\end{array}$ & $\begin{array}{c}\text { CONT-low dose } \\
(\mathbf{n}=\mathbf{1 7})\end{array}$ & $\begin{array}{c}\text { CONT-high dose } \\
(\mathbf{n}=7)\end{array}$ \\
\hline $\begin{array}{l}\text { Pre-season mean (SD) } \\
\text { BDI-II }\end{array}$ & $3.65(4.86)$ & $2.82(3.34)$ & $3.57(3.64)$ \\
PCSS & $12.05(10.79)$ & $10.00(11.03)$ & $13.43(11.27)$ \\
STAI-State & $32.35(8.25)$ & $33.88(8.00)$ & $37.14(6.04)$ \\
STAI-Trait & $37.20(10.14)$ & $35.41(7.68)$ & $37.29(10.39)$ \\
PSS & $14.25(5.37)$ & $13.94(4.85)$ & $12.57(4.08)$ \\
Post-season & mean (SD) & & \\
BDI-II & $4.50(6.72)$ & $3.35(3.89)$ & $5.00(3.83)$ \\
PCSS & $8.85(10.85)$ & $7.41(6.56)$ & $9.57(13.84)$ \\
STAI-State & $35.35(11.74)$ & $35.00(9.16)$ & $35.71(10.45)$ \\
STAI-Trait & $34.10(10.47)$ & $36.71(9.57)$ & $35.43(11.03)$ \\
PSS & $15.10(7.24)$ & $15.94(5.80)$ & $14.71(5.82)$ \\
\hline
\end{tabular}

There were no significant differences among groups in self-reported symptoms of depression, anxiety, stress, or concussion-related symptoms at pre-season or post-season, nor were there significant groupby-time interaction effects.

BDI-Il, Beck Depression Inventory-II; PCSS, Post-Concussion Symptom Scale; PSS, Perceived Stress Scale; SD, standard deviation; STAI, StateTrait Anxiety Inventory. 
exposures among midfielders and defenders relative to forwards and goal-keepers. ${ }^{53}$ Across the season, the CONT-Low Dose group sustained an average of 8.94 headers in games $(\mathrm{SD}=10.04$; range $0-34)$ whereas the CONT-High Dose group sustained an average of 70.71 headers in games $(\mathrm{SD}=24.5$, range $=48-115)$.

Pro-saccade task

When interpreting change over time on oculomotor measures, shorter latency at post- versus pre-season is reflective of faster reaction time, or improved performance. Decreased anti-saccade error rate at postversus pre-season reflects improved performance. Analysis of reflexive, pro-saccade task performance from pre- to post-season revealed a trending visitby-group-by-condition interaction effect on latency $(p=0.082)$, such that CONT-High Dose demonstrated longer average latency at post-season, relative to preseason, particularly on gap (4.90\% increase) and overlap $(3.77 \%$ increase) conditions, whereas CONT-Low Dose demonstrated more modest increases in latency (2.95\% on no gap, $1.77 \%$ on gap), and NON-CONT demonstrated a modest increase in latency on overlap trials only ( $1.81 \%$ increase, $<1 \%$ change on other trials); see Figure 1. There were no significant visit-by-group effects on pro-saccade gain, accuracy, or duration. There was a significant $(p=0.018)$ visit-by-group interaction on peak velocity (no gap condition only) in which NON-CONT demonstrated a $2.94 \%$ decrease, CONT-Low Dose demonstrated a $0.64 \%$ decrease, and CONT-High Dose demonstrated a $4.42 \%$ decrease from pre- to post-season. Notably, CONT-High Dose demonstrated faster peak velocity at pre-season assessment (mean [standard error of the mean; SEM], degrees/sec, 407.05 [3.87]) relative to pre-season peak velocity of CONT-Low Dose (384.81 [2.72]) and NON-CONT (391.43 [2.63]) groups.

\section{Anti-saccade task}

There were significant visit-by-group-by-condition $(p=0.001)$ and visit-by group $(p<0.001)$ effects on anti-saccade latency in which NON-CONT and CONT-Low Dose demonstrated shorter anti-saccade latencies from pre- to post-season, whereas CONTHigh Dose demonstrated longer latencies, with differential effects observed across conditions (Fig. 2). There was also a significant visit-by-group, although no visit-by-group-by-condition, effect on anti-saccade error rate $(p=0.021)$; however, the effect does not survive the Bonferroni correction $(p>0.0125)$. From pre- to post-season averaged across conditions, NONCONT demonstrated an average of $34.77 \%$ reduction in error rate (mean [SD] pre-season: $19.32 \%$ [13.81\%], post-season: $12.60 \%[10.89 \%])$ and CONT-Low Dose a $31.83 \%$ reduction (pre-season: $13.66 \%$ [8.86\%], postseason: $9.31 \%$ [7.89\%]), but CONT-High Dose remained stable $(<1.00 \%$ change); pre-season: $13.39 \%$ [7.07\%], post-season: $13.39 \%$ [9.28\%]); see Figure 3.

\section{Memory-guided saccade task}

There were significant visit-by-group-by-delay interval $(p<0.001)$ and visit-by group $(p<0.001)$ effects on MGS latency with groups showing pre-season to postseason improvement in a stepwise fashion such that

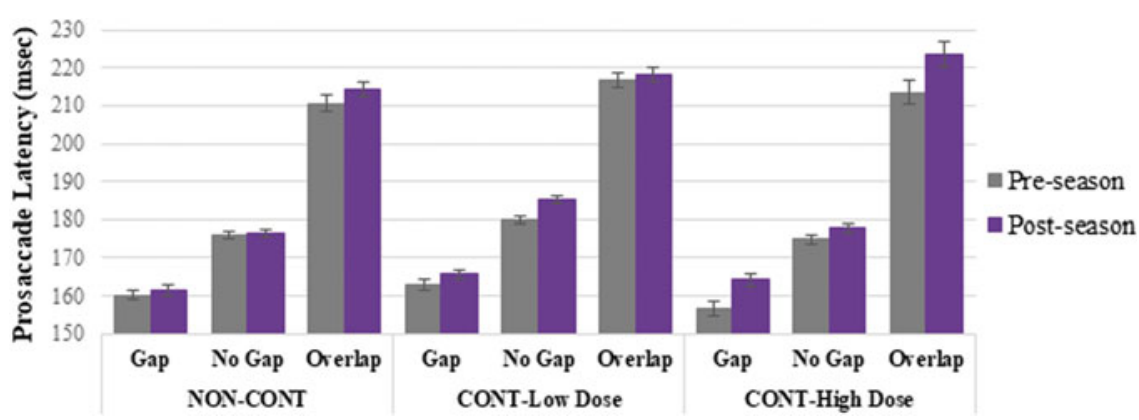

FIG. 1. Pro-saccade latency by visit, group, and condition. Error bars represent standard error of the mean. Compared to pre-season performance, CONT-High Dose trended toward longer latency at post-season particularly on gap and overlap conditions, to a greater degree than CONT-Low Dose and NON-CONT (visit-by-group-by-condition interaction effect, $p=0.082$ ). 


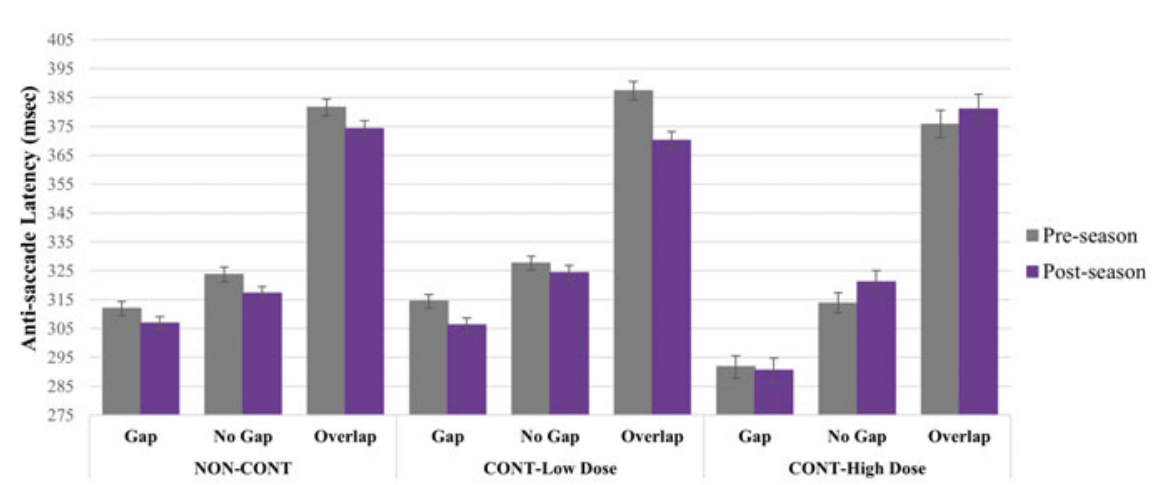

FIG. 2. Anti-saccade latency by visit, group, and condition. Error bars represent standard error of the mean. Compared with pre-season performance, NON-CONT demonstrated shorter post-season latency to a greater degree than CONT-Low Dose, whereas CONT-High Dose demonstrated longer post-season versus pre-season latency on no gap and overlap conditions (visit-by-group-by-condition effect, $p=0.001$ ).

NON-CONT demonstrated shorter pre- to post-season latencies followed by CONT-Low Dose and CONTHigh Dose, which showed minimal change (5.74\%, $2.76 \%$, and $0.79 \%$, respectively, averaged across delays). This pattern is particularly evident on shorter delay period durations (i.e., 1- and 2-sec delay durations); see Figure 4 . There were no significant visit-by-groupby-condition or visit-by group effects on MGS spatial accuracy of the primary saccade or the final resting eye position.

\section{Discussion}

In this study evaluating the use of oculomotor testing to detect differential change in cognitive and sensorimotor processing following variable exposure to head impacts over the course of a competitive season, we found that non-contact sport female athletes and female soc- cer players with relatively lower header exposure demonstrated faster oculomotor reaction time from pre- to post-season, likely attributable to practice effects, on tasks with executive functioning demands (namely, attentional control/inhibition and spatial working memory), whereas female soccer players with relatively higher header exposure remained stable or subtly declined from pre- to post-season. Similarly, compared with pre-season performance, non-contact sport athletes and soccer players with relatively lower header exposure demonstrated improvement in response inhibition, reflected by reduced anti-saccade error rate, at post-season, whereas female soccer players with relatively higher header exposure remained stable. There were no significant differences among groups in change over time on reflexive, pro-saccade reaction time, suggesting increased sensitivity of tasks with executive

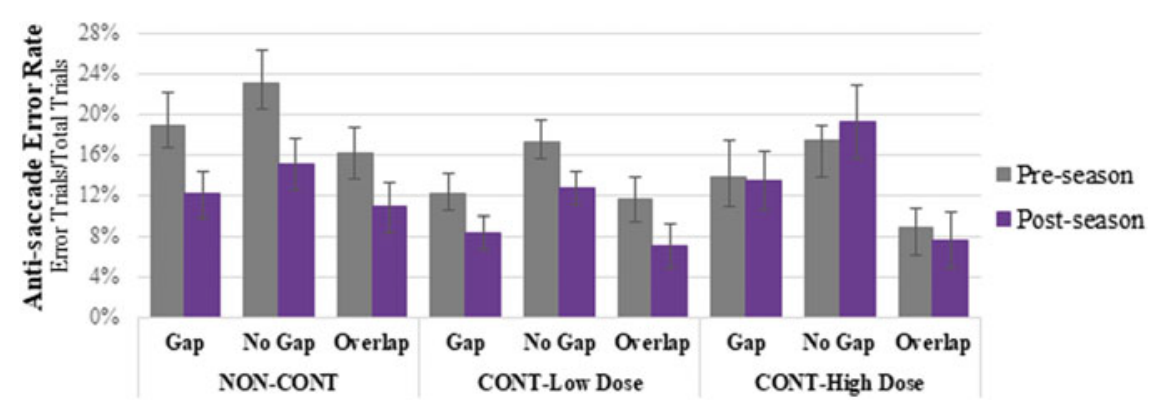

FIG. 3. Anti-saccade error rate by visit, group, and condition. Error bars represent standard deviation. Compared with pre-season performance, NON-CONT and CONT-Low Dose demonstrated greater reduction in anti-saccade error rate at post-season compared with CONT-High Dose $(p=0.021)$. 


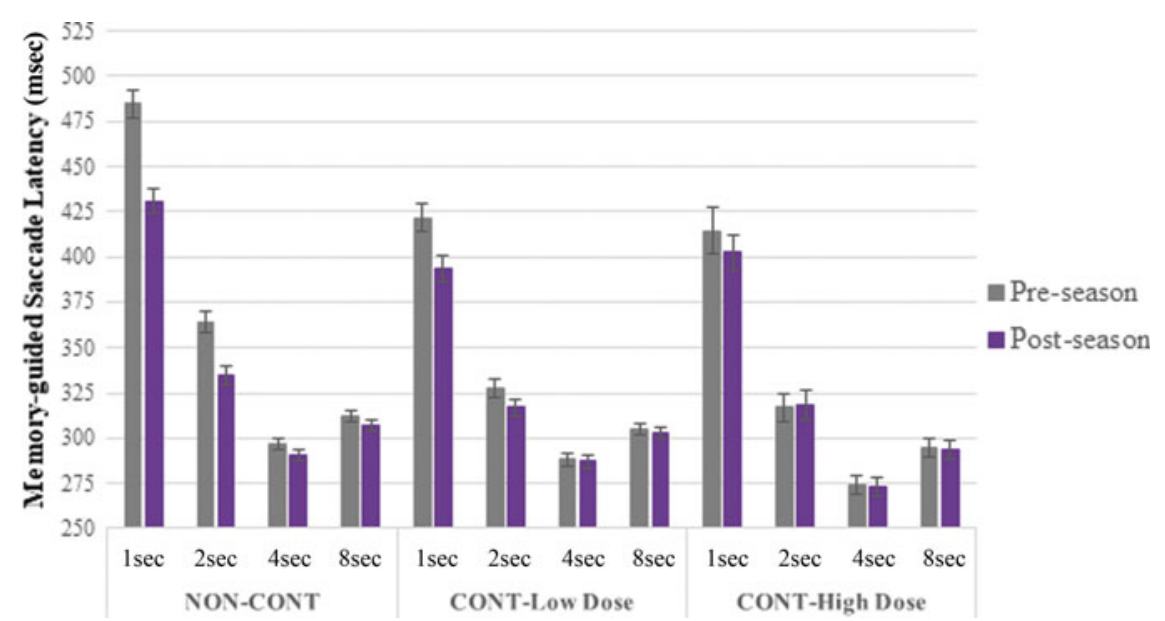

FIG. 4. Memory-guided saccade latency by visit, group, and condition (delay period interval). Error bars represent standard error of the mean. NON-CONT demonstrated $5.74 \%$ shorter, CONT-Low Dose $2.76 \%$ shorter, and CONT-High Dose $0.79 \%$ shorter average post-season versus pre-season latency, with greater effects observed on the 1-sec and 2-sec delay conditions (visit-by-group-by-condition and visit-by group effects, $p<0.001$ ).

functioning demands (anti-saccade and MGS) to the effects of head impact exposure. This is not surprising given that athletes with recent concussion do not reliably demonstrate altered pro-saccade reaction time. ${ }^{32}$

Multiple neuroimaging methodologies have detected adverse change from pre- to post-season among collision sport athletes, with change attributable to exposure to subconcussive head impacts that yield no clinical symptoms. ${ }^{9,11-13,15,54-56}$ However, prospective investigations of behavioral and/or cognitive functioning from pre- to post-season have produced mixed results. ${ }^{16,18-20,22-26}$ The results of this study suggest that oculomotor testing may possess adequate sensitivity to distinguish differential patterns of change in sensorimotor and cognitive functioning following variable exposure to impacts over the course of a female collegiate soccer season. Further, our findings were on tasks of executive functioning, which is consistent with neuroimaging literature citing alterations in neurometabolism, functional activation, and connectivity in the dorsolateral prefrontal cortex (DLPFC) as a result of subconcussive impacts. ${ }^{8,15,57}$

In our primary hypotheses, we predicted that CONT-High Dose athletes would demonstrate longer anti-saccade and MGS latencies, whereas CONT-Low Dose and NON-CONT would demonstrate stability or improvement over time. The direction of our hypotheses was supported in that the NON-CONT and
CONT-Low Dose groups demonstrated improved performance and CONT-High Dose demonstrated a subtle decline (anti-saccade latency) or remained stable (MGS latency). Greater improvement in anti-saccade latency over time among CONT-Low Dose (2.68\% shorter) relative to NON-CONT (1.84\% shorter) was surprising given that we expected athletes with any exposure to head impacts to demonstrate more adverse change relative to athletes with no exposure. This finding may be explained by marginally faster average pre-season antisaccade latency among NON-CONT (mean [SEM], $\mathrm{msec}=339.06$ [2.62]) versus CONT-Low Dose (343.12 [2.64]), thus creating greater opportunity for improvement in the CONT-Low Dose group at post-season. The CONT-High Dose group had the fastest pre-season average anti-saccade latency (327.08 [4.07]) among the three groups, which may suggest the subtle decline in performance observed from pre-season to post-season is partially due to a ceiling effect in which the opportunity for significant improvement from baseline is limited. Nonetheless, a lack of improvement from pre- to post-season among CONT-High Dose may reflect subtle adverse effects of exposure to increased headers on speed of voluntary responding, which is consistent with findings of prolonged anti-saccade latencies among participants following concussion. ${ }^{28,34,58,59}$

With regard to MGS latency, NON-CONT demonstrated $5.74 \%$ shorter, CONT-Low Dose $2.76 \%$ shorter, 
and CONT-High Dose $0.79 \%$ shorter post-season latency (averaged across conditions) compared with pre-season latency, with effects particularly apparent on trials with shorter delay durations. Similar to those on anti-saccade latency, the effects observed on MGS latency may be partially due to better performance at baseline among CONT groups (MGS latency mean [SEM], msec: CONT High Dose $=325.14$ [7.72], CONT Low Dose $=335.71$ [4.91]) relative to NON-CONT (364.48 [4.98]), leaving more opportunity for improvement among NON-CONT. However, the greater improvement among CONT-Low Dose versus High Dose suggests differential change may be partially attributable to greater relative estimated exposure to head impacts among CONT-High Dose. If differential change among groups on anti- and MGS latencies from pre- to post-season can be at least partially ascribed to varied exposure to head impacts, it suggests the cortical regions, or connections among them and their projections to subcortical areas involved in response latency of voluntary saccadic responses, including the frontal eye fields (FEF), ${ }^{60-62}$ DLPFC, ${ }^{63}$ supplementary eye fields (SEF), anterior cingulate, and intraparietal sulcus, ${ }^{60}$ may be vulnerable to the effects of subconcussive impacts.

In our primary hypotheses, we also predicted that CONT-High Dose would demonstrate increased antisaccade error rate, compared with CONT-Low Dose and NON-CONT, who would show relative stability or improvement over time. Indeed, NON-CONT and CONT-Low Dose groups demonstrated similar improvement from pre- to post-season ( $>30 \%$ reduction in error rate). However, CONT-High Dose remained stable over time, although this analysis did not survive the Bonferroni correction for multiple comparisons. Nonetheless, the lack of improvement from pre- to post-season among the CONT-High Dose group could be ascribed to greater estimated exposure to head impacts because contact groups had similar pre-season performances (anti-saccade error rate, mean [SD]: CONT High Dose $=13.39 \%$ [7.07\%], CONT-Low Dose $=13.66 \%$ [8.86\%]) and therefore, results cannot be attributed to a ceiling effect.

The discrepant change in error rate from pre- to post-season among CONT-High Dose relative to NONCONT and CONT-Low Dose groups is also consistent with the post-concussion literature that demonstrates higher anti-saccade error rates among participants with recent concussion versus controls. ${ }^{28,34,59,64}$ Therefore, the regions and their connections involved in the execution of anti-saccades-including frontal areas (particularly DLPFC, medial FEF, SEF, and middle frontal gyrus [MFG]), parietal sensorimotor areas (inferior parietal lobule), to a lesser extent subcortical areas (anterior cingulate), and the cortico-striatal pathway from the FEF to the superior colliculus (SC) involving the caudate nucleus-may be affected by exposure to subconcussive and concussive hits. ${ }^{65-72}$ Recent evidence suggests head trauma may disrupt proper functioning of cortico-striatal projections, which supports the suggestion that this mechanism may underlie the group effects observed on anti-saccade error rate. ${ }^{73,74}$

Our hypothesis that CONT groups would demonstrate differential change on MGS spatial accuracy, a measure of spatial working memory ability, relative to NON-CONT from pre- to post-season, was not supported. Given that differential change was observed among groups with varying levels of estimated exposure to head impacts on anti-saccade error rate but not on MGS spatial accuracy, it is possible that inhibitory control abilities may be more susceptible to the effects of head impact exposure relative to spatial working memory.

Overall, we detected differences over time in performance on tasks with executive functioning demands, and not on a reflexive sensory task, among athletes with higher levels of estimated exposure to head impacts over the course of a season. Specific executive functioning demands included executive control and reaction time on tasks of inhibition and working memory. Investigations of the effects of subconcussive head impacts on executive functioning and processing speed using traditional or computerized neuropsychological measures have generally not revealed significant findings. ${ }^{75}$ This suggests that eye movement testing may have greater sensitivity to subtle differences in executive functioning changes. Further, taking together neuroimaging evidence revealing altered structure and function in DLPFC following subconcussive impact exposure and the known role of DLPFC in the execution, and to some extent, speed of anti-saccades, the results of our study suggest subconcussive impacts may affect functioning associated with DLPFC. $8,57,61,71,76$

\section{Conclusion}

In summary, NON-CONT and CONT-Low Dose groups both demonstrated improved performance, likely attributable to practice effects, from pre-season to post-season on oculomotor measures of reaction time and attentional control, whereas CONT-High Dose did not show improvement on these measures. Differential changes were not attributable to variations in mood, somatic, 
or physical symptoms at times of assessment or preexisting history of concussion, ADHD, or learning disability (see Tables 2 and 3). Therefore, the lack of improvement among the CONT-High Dose athletes, with the greatest estimated exposure to head impacts over the course of the season, may be interpreted as a negative consequence of elevated exposure to head trauma. Although the aforementioned effects were statistically significant, the magnitude of effects was quite small, so likely not clinically significant. This is not surprising given that the CONT-High Dose group did not report increased concussion-related physical, somatic, mood, or sleep symptoms from pre- to post-season (Table 3). The similar change in performance over time between noncontact sport athletes and female soccer players with relative lower exposure to headers suggests a dose-dependent effect, where lower levels of exposure to head impacts may not yield adverse change over time in terms of oculomotor reaction time and attentional control.

\section{Limitations}

Certain study limitations warrant mention. First, although we were able to quantify headers incurred during games, we did not quantify soccer headers sustained during practice sessions nor were we able to collect information regarding the magnitude and location of head impacts. It is likely, and anecdotally reported by the senior athletic trainers, that players who sustain more headers in games also sustain more headers in practices, but we lack quantitative data to support that claim. Further, players may have sustained non-header head impacts (e.g., collision with other players) that are not accounted for. Second, it is possible that female athletes who engage in "ball" sports may have faster reaction times in response to external stimuli; our control, noncontact athlete group consisted of tennis, golf, and swimming athletes, whose performance on our tasks may be influenced by the unique oculomotor and reaction time demands of their respective sport. This could be addressed in future studies that restrict the control group to only ball or non-ball sports. Third, pre-existing visual disturbances were not evaluated outside of participant self-reported problems with vision. Future directions of this research include expanding the protocol to a larger sample size, adding follow-up oculomotor assessments to evaluate the extent to which disparate performances from pre- to post-season may normalize after a period of rest from exposure to subconcussive hits, and expansion to youth, professional, and male athletes.

\section{Acknowledgments}

The content is solely the responsibility of the authors and does not necessarily represent the official views of the National Institutes of Health.

\section{Funding Information}

This work was funded by the Eleanor Wood-Prince Grant Initiative: A Project of the Woman's Board of Northwestern Memorial Hospital (to A.A.H. and J.L.R.) and supported by the National Institute Of Neurological Disorders and Stroke of the National Institutes of Health under award number F31NS106840 (to V.T.G.).

\section{Author Disclosure Statement}

No competing financial interests exist.

\section{Supplementary Materials}

Supplementary Appendix S1

Supplementary Figure S1

\section{References}

1. Asken, B.M., Sullan, M.J., DeKosky, S.T., Jaffee, M.S., and Bauer, R.M. (2017). Research gaps and controversies in chronic traumatic encephalopathy: a review. JAMA Neurol. 74, 1255-1262.

2. Baugh, C.M., Stamm, J.M., Riley, D.O., Gavett, B.E., Shenton, M.E., Lin, A., Nowinski, C.J., Cantu, R.C., McKee, A.C., and Stern, R.A. (2012). Chronic traumatic encephalopathy: neurodegeneration following repetitive concussive and subconcussive brain trauma. Brain Imaging Behav. 6, 244-254.

3. McKee, A.C., Alosco, M.L., and Huber, B.R. (2016). Repetitive head impacts and chronic traumatic encephalopathy. Neurosurg. Clin. N. Am. 27, 529-535.

4. Randolph, C. (2014). Is chronic traumatic encephalopathy a real disease? Curr. Sports Med. Rep. 13, 33-37.

5. Hart, J., Kraut, M.A., Womack, K.B., Strain, J., Didehbani, N., Bartz, E., Conover, H., Mansinghani, S., Lu, H., and Cullum, C.M. (2013). Neuroimaging of cognitive dysfunction and depression in aging retired NFL players: a cross-sectional study. JAMA Neurol. 70, 326-335.

6. McKee, A.C., Cantu, R.C., Nowinski, C.J., Hedley-Whyte, E.T., Gavett, B.E., Budson, A.E., Santini, V.E., Lee, H.-S., Kubilus, C.A., and Stern, R.A. (2009). Chronic traumatic encephalopathy in athletes: progressive tauopathy after repetitive head injury. J. Neuropathol. Exp. Neurol. 68, 709-735.

7. Montenigro, P.H., Alosco, M.L., Martin, B.M., Daneshvar, D.H., Mez, J., Chaisson, C.E., Nowinski, C.J., Au, R., McKee, A.C., Cantu, R.C., McClean, M.D., Stern, R.A., and Tripodis, Y. (2017). Cumulative head impact exposure predicts later-life depression, apathy, executive dysfunction, and cognitive impairment in former high school and college football players. J. Neurotrauma 34, 328-340.

8. Bari, S., Svaldi, D.O., Jang, I., Shenk, T.E., Poole, V.N., Lee, T., Dydak, U., Rispoli, J.V., Nauman, E.A., and Talavage, T.M. (2018). Dependence on subconcussive impacts of brain metabolism in collision sport athletes: an MR spectroscopic study. Brain Imaging Behav. 13, 735-739.

9. Bazarian, J.J., Zhu, T., Zhong, J., Janigro, D., Rozen, E., Roberts, A., Javien, H., Merchant-Borna, K., Abar, B., and Blackman, E.G. (2014). Persistent, longterm cerebral white matter changes after sports-related repetitive head impacts. PLoS One 9, e94734.

10. Chun, I.Y., Mao, X., Breedlove, E.L., Leverenz, L.J., Nauman, E.A., and Talavage, T.M. (2015). DTI detection of longitudinal WM abnormalities due to accumulated head impacts. Dev. Neuropsychol. 40, 92-97.

11. Davenport, E.M., Whitlow, C.T., Urban, J.E., Espeland, M.A., Jung, Y., Rosenbaum, D.A., Gioia, G.A., Powers, A.K., Stitzel, J.D., and Maldjian, J.A. (2014). Abnormal white matter integrity related to head impact exposure in a season of high school varsity football. J. Neurotrauma 31, 1617-1624. 
12. Merchant-Borna, K., Asselin, P., Narayan, D., Abar, B., Jones, C.M.C., and Bazarian, J.J. (2016). Novel method of weighting cumulative helmet impacts improves correlation with brain white matter changes after one football season of sub-concussive head blows. Ann. Biomed. Eng. 44, 3679-3692.

13. Shenk, T.E., Robinson, M.E., Svaldi, D.O., Abbas, K., Breedlove, K.M., Leverenz, L.J., Nauman, E.A., and Talavage, T.M. (2015). FMRI of visual working memory in high school football players. Dev. Neuropsychol. 40, 63-68.

14. Sollmann, N., Echlin, P.S., Schultz, V., Viher, P.V., Lyall, A.E., Tripodis, Y., Kaufmann, D., Hartl, E., Kinzel, P., Forwell, L.A., Johnson, A.M., Skopelja, E.N., Lepage, C., Bouix, S., Pasternak, O., Lin, A.P., Shenton, M.E., and Koerte, I.K. (2018). Sex differences in white matter alterations following repetitive subconcussive head impacts in collegiate ice hockey players. Neurolmage Clin. 17, 642-649.

15. Talavage, T.M., Nauman, E.A., Breedlove, E.L., Yoruk, U., Dye, A.E., Morigaki, K.E., Feuer, H., and Leverenz, L.J. (2014). Functionally-detected cognitive impairment in high school football players without clinically-diagnosed concussion. J. Neurotrauma 31, 327-338.

16. McAllister, T.W., Flashman, L.A., Maerlender, A., Greenwald, R.M., Beckwith, J.G., Tosteson, T.D., Crisco, J.J., Brolinson, P.G., Duma, S.M., Duhaime, A.-C., Grove, M.R., and Turco, J.H. (2012). Cognitive effects of one season of head impacts in a cohort of collegiate contact sport athletes. Neurology 78, 1777-1784.

17. Ravdin, L.D., Barr, W.B., Jordan, B., Lathan, W.E., and Relkin, N.R. (2003). Assessment of cognitive recovery following sports related head trauma in boxers. Clin. J. Sport Med. 13, 21-27.

18. Vogelpohl, R.E., Lindsey, R.A., Stickley, C.D., Hetzler, R.K., Williams, W., and Kimura, I.F. (2017). A prospective evaluation on the effects of one high school football season on neurocognitive test scores in high school football athletes. Int. J. Athl. Ther. Train. 22, 49-55.

19. Long, A.S., Niemeier, J.P., McWilliams, A., Patterson, C.G., Perrin, P., Templin, M., and Price, D.E. (2019). Comparison of neurocognitive changes over one competitive season in adolescent contact and non-contact athletes. Athl. Train. Sports Health Care 11, 28-36.

20. White-Schwoch, T., Krizman, J., McCracken, K., Burgess, J.K., Thompson, E.C., Nicol, T., LaBella, C.R., and Kraus, N. (2020). Performance on auditory, vestibular, and visual tests is stable across two seasons of youth tackle football. Brain Inj. 34, 236-244.

21. Chrisman, S.P.D., Mac Donald, C.L., Friedman, S., Andre, J., Rowhani-Rahbar, A., Drescher, S., Stein, E., Holm, M., Evans, N., Poliakov, A.V., Ching, R.P., Schwien, C.C., Vavilala, M.S., and Rivara, F.P. (2016). Head impact exposure during a weekend youth soccer tournament. J. Child Neurol. 31, 971-978.

22. Munce, T.A., Dorman, J.C., Odney, T.O., Thompson, P.A., Valentine, V.D., and Bergeron, M.F. (2014). Effects of youth football on selected clinical measures of neurologic function: a pilot study. J. Child Neurol. 29, 1601-1607.

23. Gysland, S.M., Mihalik, J.P., Register-Mihalik, J.K., Trulock, S.C., Shields, E.W., and Guskiewicz, K.M. (2012). The relationship between subconcussive impacts and concussion history on clinical measures of neurologic function in collegiate football players. Ann. Biomed. Eng. 40, 14-22.

24. Miller, J.R., Adamson, G.J., Pink, M.M., and Sweet, J.C. (2007). Comparison of preseason, midseason, and postseason neurocognitive scores in uninjured collegiate football players. Am. J. Sports Med. 35, 1284-1288.

25. Broglio, S.P., Williams, R., Rettmann, A., Moore, B., Eckner, J.T., and Meehan, S. (2018). No seasonal changes in cognitive functioning among high school football athletes: implementation of a novel electrophysiological measure and standard clinical measures. Clin. J. Sport Med. 28, 130

26. Diakogeorgiou, E., and Miyashita, T.L. (2018). Effect of Head Impact Exposures on Changes in Cognitive Testing. Orthop. J. Sports Med. 6, 2325967118761031.

27. Cifu, D.X., Wares, J.R., Hoke, K.W., Wetzel, P.A., Gitchel, G., and Carne, W. (2015). Differential eye movements in mild traumatic brain injury versus normal controls. J. Head Trauma Rehabil. 30, 21-28.

28. Heitger, M., Anderson, T.J., Jones, R.D., Dalrymple-Alford, J.C., Frampton, C.M., and Ardagh, M.W. (2004). Eye movement and visuomotor arm movement deficits following mild closed head injury. Brain 127, 575-590.

29. Johnson, B., Zhang, K., Hallett, M., and Slobounov, S. (2015). Functional neuroimaging of acute oculomotor deficits in concussed athletes. Brain Imaging Behav. 9, 564-573.

30. Heitger, M.H., Jones, R.D., and Anderson, T.J. (2008). A new approach to predicting postconcussion syndrome after mild traumatic brain injury based upon eye movement function. Annu. Int. Conf. IEEE Eng. Med. Biol. Soc. 2008, 3570-3573.
31. Munoz, D., Armstrong, I., and Coe, B. (2007). Using eye movements to probe development and dysfunction., in: R. Van Gompel, M. Fischer, W. Murray, and R. Hill. (eds). Eye Movements. Elsevier: Oxford, pps. 99-124.

32. Snegireva, N., Derman, W., Patricios, J., and Welman, K.E. (2018). Eye tracking technology in sports-related concussion: a systematic review and meta-analysis. Physiol. Meas. 39, 12TR01.

33. Drew, A.S., Langan, J., Halterman, C., Osternig, L.R., Chou, L.-S., and van Donkelaar, P. (2007). Attentional disengagement dysfunction following mTBI assessed with the gap saccade task. Neurosci. Lett. 417, 61-65.

34. Webb, B., Humphreys, D., and Heath, M. (2018). Oculomotor executive dysfunction during the early and later stages of sport-related concussion recovery. J. Neurotrauma 35, 1874-1881.

35. Hoffer, M.E., Balaban, C., Szczupak, M., Buskirk, J., Snapp, H., Crawford, J., Wise, S., Murphy, S., Marshall, K., Pelusso, C., Knowles, S., and Kiderman, A. (2017). The use of oculomotor, vestibular, and reaction time tests to assess mild traumatic brain injury (mTBI) over time. Laryngoscope Investig. Otolaryngol. 2, 157-165.

36. Clough, M., Mutimer, S., Wright, D.K., Tsang, A., Costello, D.M., Gardner, A.J., Stanwell, P., Mychasiuk, R., Sun, M., Brady, R.D., McDonald, S.J., Webster, K.M., Johnstone, M.R., Semple, B.D., Agoston, D.V., White, O.B., Frayne, R., Fielding, J., O'Brien, T.J., and Shultz, S.R. (2017). Oculomotor cognitive control abnormalities in Australian rules football players with a history of concussion. J. Neurotrauma 35, 730-738.

37. Ettenhofer, M.L., and Barry, D.M. (2016). Saccadic impairment associated with remote history of mild traumatic brain injury. J. Neuropsychiatry Clin. Neurosci. 28, 223-231.

38. Ledwidge, P., Patterson, J., Molfese, D., and Honaker, J. (2019). Clinical utility of oculomotor and electrophysiological measures in identifying concussion history. Clin. J. Sport Med., 29, 292-297.

39. Williams, I.M., Ponsford, J.L., Gibson, K.L., Mulhall, L.E., Curran, C.A., and Abel, L.A. (1997). Cerebral control of saccades and neuropsychological test results after head injury. J. Clin. Neurosci. 4, 186-196.

40. Reilly, J.L., Harris, M.S.H., Khine, T.T., Keshavan, M.S., and Sweeney, J.A. (2008). Reduced attentional engagement contributes to deficits in prefrontal inhibitory control in schizophrenia. Biol. Psychiatry 63, 776-783.

41. Reilly, J.L., Frankovich, K., Hill, S., Gershon, E.S., Keefe, R.S.E., Keshavan, M.S., Pearlson, G.D., Tamminga, C.A., and Sweeney, J.A. (2014). Elevated antisaccade error rate as an intermediate phenotype for psychosis across diagnostic categories. Schizophr. Bull. 40, 1011-1021.

42. Lunn, J., Donovan, T., Litchfield, D., Lewis, C., Davies, R., and Crawford, T. (2016). Saccadic eye movement abnormalities in children with epilepsy. PLoS One 11, e0160508.

43. Lovell, M.R., Iverson, G.L., Collins, M.W., Podell, K., Johnston, K.M., Pardini, D., Pardini, J., Norwig, J., and Maroon, J.C. (2006). Measurement of symptoms following sports-related concussion: reliability and normative data for the Post-Concussion Scale. Appl. Neuropsychol. 13, 166-174.

44. Beck, A.T., Steer, R.A., Ball, R., and Ranieri, W.F. (1996). Comparison of Beck Depression Inventories-IA and-II in psychiatric outpatients. J. Pers. Assess. 67, 588-597.

45. Sprinkle, S.D., Lurie, D., Insko, S.L., Atkinson, G., Jones, G.L., Logan, A.R., and Bissada, N.N. (2002). Criterion validity, severity cut scores, and test-retest reliability of the Beck Depression Inventory-II in a university counseling center sample. J. Couns. Psychol. 49, 381-385.

46. Spielberger, C.D. (2010). State-Trait Anxiety Inventory, in: The Corsini Encyclopedia of Psychology. American Cancer Society, p. 1.

47. Cohen, S., Kamarck, T., and Mermelstein, R. (1983). A global measure of perceived stress. J. Health Soc. Behav. 24, 385-396.

48. Lee, E.-H. (2012). Review of the psychometric evidence of the Perceived Stress Scale. Asian Nurs. Res. 6, 121-127.

49. Karpouzian-Rogers, T., Stocks, J., Meltzer, H.Y., and Reilly, J.L. (2020). The effect of high vs. low dose lurasidone on eye movement biomarkers of prefrontal abilities in treatment-resistant schizophrenia. Schizophr. Res. 215, 314-321.

50. (2017). IBM SPSS Statistics of Windows. Armonk, NY: IBM Corp.

51. Ferron, J., Dailey, R., and Yi, Q. (2002). Effects of misspecifying the firstlevel error structure in two-level models of change. Multivar. Behav. Res. 37, 379-403.

52. McCuen, E., Svaldi, D., Breedlove, K., Kraz, N., Cummiskey, B., Breedlove, E.L., Traver, J., Desmond, K.F., Hannemann, R.E., Zanath, E., Guerra, A., Leverenz, L., Talavage, T.M., and Nauman, E.A. (2015). Collegiate women's soccer players suffer greater cumulative head impacts than their high school counterparts. J. Biomech. 48, 3720-3723. 
53. Lamond, L.C., Caccese, J.B., Buckley, T.A., Glutting, J., and Kaminski, T.W. (2018). Linear acceleration in direct head contact across impact type, player position, and playing scenario in collegiate women's soccer players. J. Athl. Train. 53, 115-121.

54. Davenport, E.M., Apkarian, K., Whitlow, C.T., Urban, J.E., Jensen, J.H., Szuch, E., Espeland, M.A., Jung, Y., Rosenbaum, D.A., Gioia, G.A., Powers, A.K., Stitzel, J.D., and Maldjian, J.A. (2016). Abnormalities in diffusional kurtosis metrics related to head impact exposure in a season of high school varsity football. J. Neurotrauma 33, 2133-2146.

55. Davenport, E.M., Urban, J.E., Mokhtari, F., Lowther, E.L., Van Horn, J.D., Vaughan, C.G., Gioia, G.A., Whitlow, C.T., Stitzel, J.D., and Maldjian, J.A. (2016). Subconcussive impacts and imaging findings over a season of contact sports. Concussion 1, CNC19.

56. Lipton, M.L., Kim, N., Zimmerman, M.E., Kim, M., Stewart, W.F., Branch, C.A., and Lipton, R.B. (2013). Soccer heading is associated with white matter microstructural and cognitive abnormalities. Radiology 268, 850-857.

57. Johnson, B., Neuberger, T., Gay, M., Hallett, M., and Slobounov, S. (2014). Effects of subconcussive head trauma on the default mode network of the brain. J. Neurotrauma 31, 1907-1913.

58. Landry, A.P., Ting, W.K.C., Zador, Z., Sadeghian, A., and Cusimano, M.D. (2018). Using artificial neural networks to identify patients with concussion and postconcussion syndrome based on antisaccades. J. Neurosurg. $1,1-8$

59. Ting, W.K.-C., Schweizer, T.A., Topolovec-Vranic, J., and Cusimano, M.D. (2016). Antisaccadic eye movements are correlated with corpus callosum white matter mean diffusivity, stroop performance, and symptom burden in mild traumatic brain injury and concussion. Front. Neurol. 6, 271.

60. Jamadar, S.D., Johnson, B.P., Clough, M., Egan, G.F., and Fielding, J. (2015). Behavioral and neural plasticity of ocular motor control: changes in performance and $\mathrm{fMRI}$ activity following antisaccade training. Front. Hum. Neurosci. 9, 653 .

61. Pierrot-Deseilligny, C., Ploner, C.J., Müri, R.M., Gaymard, B., and RivaudPéchoux, S. (2002). Effects of cortical lesions on saccadic. Ann. N. Y. Acad. Sci. 956, 216-229.

62. Pierrot-Deseilligny, C., Rivaud, S., Gaymard, B., and Agid, Y. (1991). Cortical control of reflexive visually-guided saccades. Brain J. Neurol. 114 (Pt. 3), 1473-1485.

63. Ploner, C.J., Gaymard, B.M., Rivaud-Péchoux, S., and Pierrot-Deseilligny, C (2005). The prefrontal substrate of reflexive saccade inhibition in humans. Biol. Psychiatry 57, 1159-1165.

64. Balaban, C., Hoffer, M.E., Szczupak, M., Snapp, H., Crawford, J., Murphy, S., Marshall, K., Pelusso, C., Knowles, S., and Kiderman, A. (2016). Oculomotor, vestibular, and reaction time tests in mild traumatic brain injury. PLoS One 11, e0162168.

65. Cornelissen, F.W., Kimmig, H., Schira, M., Rutschmann, R.M., Maguire, R.P Broerse, A., Boer, J.A.D., and Greenlee, M.W. (2002). Event-related fMRI responses in the human frontal eye fields in a randomized pro- and antisaccade task. Exp. Brain Res. 145, 270-274.

66. de Weijer, A.D., Mandl, R.C.W., Sommer, I.E.C., Vink, M., Kahn, R.S., and Neggers, S.F.W. (2010). Human fronto-tectal and fronto-striatal-tectal pathways activate differently during anti-saccades. Front. Hum. Neurosci. 4, 41

67. DeSouza, J.F.X., Menon, R.S., and Everling, S. (2003). Preparatory set associated with pro-saccades and anti-saccades in humans investigated with event-related FMRI. J. Neurophysiol. 89, 1016-1023.

68. Ford, K.A., Goltz, H.C., Brown, M.R.G., and Everling, S. (2005). Neural processes associated with antisaccade task performance investigated with event-related FMRI. J. Neurophysiol. 94, 429-440.

69. McDowell, J.E., Kissler, J.M., Berg, P., Dyckman, K.A., Gao, Y., Rockstroh, B. and Clementz, B.A. (2005). Electroencephalography/ magnetoencephalography study of cortical activities preceding prosaccades and antisaccades. Neuroreport 16, 663-668.

70. Medendorp, W.P., Goltz, H.C., and Vilis, T. (2005). Remapping the remembered target location for anti-saccades in human posterior parietal cortex. J. Neurophysiol. 94, 734-740.

71. Munoz, D.P., and Everling, S. (2004). Look away: the anti-saccade task and the voluntary control of eye movement. Nat. Rev. Neurosci. 5, 218228.

72. Schaeffer, D.J., Amlung, M.T., Li, Q., Krafft, C.E., Austin, B.P., Dyckman, K.A., and McDowell, J.E. (2013). Neural correlates of behavioral variation in healthy adults' antisaccade performance. Psychophysiology 50, 325333.
73. Bales, J.W., Wagner, A.K., Kline, A.E., and Dixon, C.E. (2009). Persistent cognitive dysfunction after traumatic brain injury: a dopamine hypothesis. Neurosci. Biobehav. Rev. 33, 981-1003.

74. Ware, A.L., Biekman, B., Hachey, R., MacLeod, M., Bird, W., Pathak, S., Clarke, E., Borrasso, A., Puccio, A.M., Glavin, K., Pomiecko, K., Moretti, P. Beers, S.R., Levin, H.S., Schneider, W., Okonkwo, D.O., and Wilde, E.A. (2018). A preliminary high-definition fiber tracking study of the executive control network in blast-induced traumatic brain injury. J. Neurotrauma 36, 686-701.

75. Mainwaring, L., Ferdinand Pennock, K.M., Mylabathula, S., and Alavie, B.Z. (2018). Subconcussive head impacts in sport: a systematic review of the evidence. Int. J. Psychophysiol. 132, 39-54.

76. Poole, V.N., Abbas, K., Shenk, T.E., Breedlove, E.L., Breedlove, K.M., Robinson, M.E., Leverenz, L.J., Nauman, E.A., Talavage, T.M., and Dydak, U. (2014). MR spectroscopic evidence of brain injury in the non-diagnosed collision sport athlete. Dev. Neuropsychol. 39, 459-473.

Cite this article as: Gallagher VT, Murthy $\mathrm{P}$, Stocks J, Vesci $B$, Colegrove D, Mjaanes J, Chen Y, Breiter H, LaBella C, Herrold AA, and Reilly JL (2020) Differential change in oculomotor performance among female collegiate soccer players versus non-contact athletes from pre- to post-season, Neurotrauma Reports 1:1, 169-180, DOI:10.1089/neur.2020.00051.

$\begin{aligned} & \text { Abbreviations Used } \\ & \text { ADHD }=\text { attention-deficit/hyperactivity disorder } \\ & \mathrm{AIC}=\text { Akaike Information Criteria } \\ & \mathrm{BDI}-\mathrm{II}=\text { Beck Depression Inventory-II } \\ & \text { CONT-High Dose }=\text { athletes who sustained }>40 \text { headers } \\ & \text { in games/season } \quad \text { in games/season } \\ & \text { CONT-Low Dose }=\text { athletes who sustained } \leq 40 \text { headers } \\ & \text { DLPFC }=\text { dorsolateral prefrontal cortex } \\ & \mathrm{FEF}=\text { frontal eye fields } \\ & \mathrm{Hx}=\text { History } \\ & \mathrm{MFG}=\text { middle frontal gyrus } \\ & \mathrm{MGS}=\text { memory-guided saccade } \\ & \mathrm{NON}-\mathrm{CONT}=\text { non-contact sport athletes } \\ & \mathrm{PCSS}=\text { Post-Concussion Symptom Scale } \\ & \mathrm{PSS}=\text { Perceived Stress Scale } \\ & \mathrm{SD}=\text { standard deviation } \\ & \mathrm{SEF}=\text { supplementary eye fields } \\ & \mathrm{SEM}=\text { standard error of the mean } \\ & \mathrm{STAI}=\text { State-Trait Anxiety Inventory }\end{aligned}$

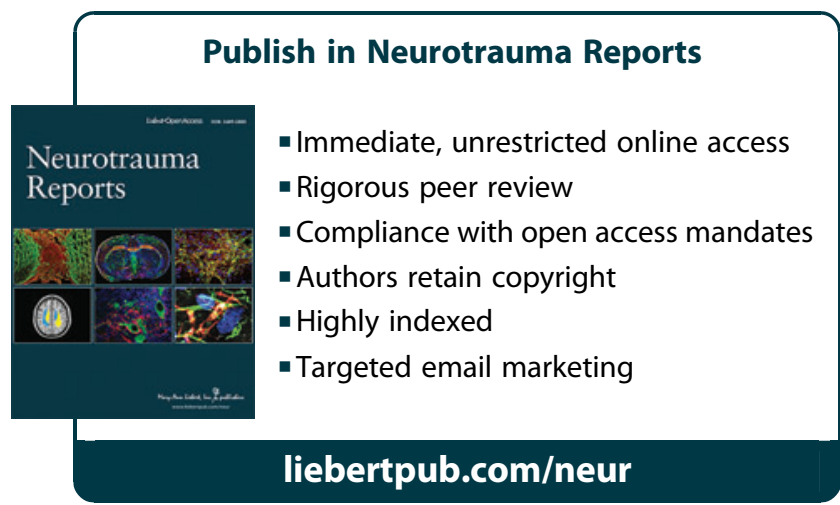

